\title{
Envelhecimento bem-sucedido e as aprendizagens no esporte competitivo: uma forma de adaptação de atletas que praticam corrida
}

Well-succeeded aging and learning processes in competition sports: means of adaptation among athletes who practice running

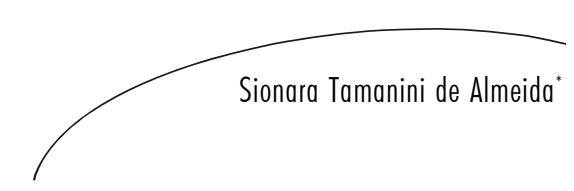

Resumo

Um arranjo conceitual que descreve o processo de envelhecimento bem-sucedido na perspectiva life-span é o modelo de estratégias denominado de seleção, otimização e compensação. Tais estratégias evocam maneiras de alcançar objetivos de vida e promovem crescimento pessoal. Compensar ou otimizar atitudes através das aprendizagens é o foco do estudo que teve como objetivo investigar as aprendizagens de atletas durante os anos de prática da modalidade esportiva da corrida através de uma pesquisa qualitativa realizada com atletas do sexo masculino provenientes de diferentes clubes e sociedades esportivas do Brasil. A coleta de dados foi realizada por meio de uma entrevista semiestruturada e de um questionário sociodemográfico, após uma triagem realizada com 83 atletas. $\mathrm{O}$ grupo de 11 atletas entrevistados $(\bar{\chi}=59,91 ; \mathrm{DP}=$ $\pm 10,58$ anos) demonstrou em suas respostas diferentes tipos de aprendizagens que garantiram desenvolvimento pessoal e no esporte e os auxiliaram em atividades cotidianas. Além disso, para desenvolver essas aprendizagens, os atletas utilizaram vários tipos de espaços e pessoas, o que demonstrou que eles são seres autônomos diante do seu aprendizado e vão à busca da solução para seus problemas.

\section{Abstract}

A conceptual arrangement which describes well-succeeded aging in the lifespan perspective is the model of strategies called selection, optimization and compensation. Such strategies evoke ways of attaining goals in life and promote personal growing. Compensating and optimizing attitudes through learning processes is the focus of this study, whose purpose is to analyze the athletes' learning processes in years of running practice through a qualitative research of male subjects from different clubs and sporting societies in Brazil. Data collection

\footnotetext{
Curso de Pós-graduação em Educação. Universidade Federal do Rio Grande do Sul. Porto Alegre, RS, Brasil.

Agência financiadora do projeto: Capes - Coordenação de Aperfeiçoamento de Pessoal de Nível Superior.
}

\author{
Palavras-chave: Medicina \\ do comportamento . saúde \\ do idoso . Medicina \\ esportiva. Envelhecimento. \\ Aprendizagem. Psicologia \\ do desenvolvimento.
}


was made through half-structured interviews and through sociodemographic questionnaires, after a screening involving 83 athletes. The group of 11 athletes interviewed ( $=59.91$; DP $= \pm 10.58$ age) has shown different kinds of learning processes which provided personal and sporting development, and helped them to cope with daily activities. Moreover, in order to develop these learning processes they used many kinds of spaces and people, what showed their selfgovernment in terms of learning and their search for solving problems.
Key-words: Behavioral Medicine. Health of the Elderly . Sports Medicine. Aging. Learning. Development phsychology.
INTRODUÇÃOO

O presente artigo é uma fração da dissertação de mestrado desenvolvida no Programa de PósGraduação em Educação da Universidade Federal do Rio Grande do Sul, acerca do envelhecimento de atletas corredores. A base teórica utilizada foi a perspectiva life-span - psicologia do desenvolvimento/ envelhecimento - quando analisada de uma forma mais geral, e o metamodelo de seleção, otimização e compensação, mais especificamente, que operacionaliza a crença da life-span no âmbito do envelhecimento bem-sucedido. ${ }^{1,2}$

O envelhecimento da população em geral, assim como o envelhecimento do atleta na perspectiva da psicologia do desenvolvimento, confere um contexto que ultrapassa a ideia de os indivíduos apenas alcançarem uma faixa de idade - no caso, os 60 anos. Ela engloba, além de aspectos físicos, os psicológicos, os biológicos, os culturais e os sociais, interferindo nas pessoas de forma contínua, com início no nascimento e término na morte do indivíduo.

De acordo com a perspectiva teórica, o envelhecimento faz parte do processo de desenvolvimento, o qual apresenta uma expressão conjunta de características de crescimento (ganhos) e declínios (perdas). Nenhuma fase do desenvolvimento humano apresenta apenas ganhos ou é somente contemplada por perdas, e essa balança deverá ser equilibrada através de capacidades adaptativas que o sujeito possui e que foram denominadas por Baltes como o modelo de seletiva otimização com compensação (Modelo SOC). ${ }^{2,3}$
Esse modelo pode ser observado, no dia a dia das pessoas, através de atitudes, com os indivíduos se adaptando às intempéries da vida e conseguindo atingir os objetivos pessoais.

No caso específico dos atletas com mais de 45 anos de idade, eles se encontram numa situação particular. Ao mesmo tempo em que o atleta treina para melhorar seu desempenho e realmente melhora, devido à reserva física que aumenta sua performance, ele também apresenta a influência do processo de envelhecimento que pode, agregado ou não a outros fatores, diminuir o desempenho esportivo. Nesse sentido, o atleta enfrenta duas tendências: uma relativa à melhora através do treino e com isso otimiza as capacidades físicas, e outra de diminuição, que exige do sujeito a ação de se adaptar a perdas e/ ou ganhos relativos a sua prática esportiva.

A adaptação significa aprender a viver em uma nova situação (boa ou má) ou com alguma limitação. ${ }^{4}$ Ao mesmo tempo, para que ela ocorra, devem-se explorar as possibilidades individuais dos sujeitos em direção a essa adaptação. $\mathrm{O}$ metamodelo de seleção, otimização e compensação oferece uma estrutura básica para pensar os processos adaptativos do desenvolvimento/ envelhecimento. Tais estratégias foram enunciadas pelos atletas e estão disponíveis em outros artigos. ${ }^{5,6}$ No entanto, a forma como ela acontece perpassa questões relativas à educação e aos processos de aprendizagem que os sujeitos vivenciam. A educação pode ser pensada de forma ampliada, na qual os espaços educativos também se diversificam, com a educação se desenvolvendo ao longo de toda a vida, como o desenvolvimento.? 
Sendo assim, o presente artigo se destina a responder às seguintes questões: os atletas pesquisados desenvolveram algum tipo de aprendizagem frente aos anos que praticaram a corrida? E de que forma foram captadas as informações necessárias para que os atletas continuassem, na prática esportiva, se mantendo competitivos ou mantendo o nível de funcionalidade?

\section{METODOLOGIA}

O estudo apresenta, principalmente, características da pesquisa qualitativa para a compreensão, de forma detalhada, dos significados e características situacionais apresentadas pelos sujeitos. ${ }^{8}$ Como essência do estudo, estão a descrição e a visão de processo. ${ }^{9}$

A pesquisa apresentou duas fases: na primeira, foram avaliados 83 atletas corredores (corridas de velocidade ou fundistas) do sexo masculino, participantes de competições esportivas, com idades variando entre 45 a 78 anos $(\bar{\chi}=54,22$; $\mathrm{DP}= \pm 8,17$ anos). Os atletas foram provenientes de diferentes localidades do Brasil (Paraná, Bahia, Rio Grande do Sul e São Paulo). Para segunda fase da pesquisa, foram entrevistados 11 atletas $(\bar{\chi}=59,91 ; \mathrm{DP}= \pm 10,58$ anos $)$ dos 83 triados.

Como instrumentos de coleta, foram utilizados três: um contendo informações sociodemográficas (dados gerais do atleta; sobre treinamento; informações sobre saúde); um inventário de triagem e uma entrevista semiestruturada. $\mathrm{O}$ inventário apresentava uma ficha composta de 12 itens que avaliavam as três estratégias de gerenciamento de vida propostas por Baltes - seleção (eletiva e baseada em perdas), otimização e compensação - o modelo SOC. Quando no preenchimento, a resposta foi indicada através da escolha entre duas frases que demonstravam atitudes do dia a dia do indivíduo. Dessa forma, o atleta deveria escolher aquela que mais se aproximava do seu modo de agir. A entrevista semiestruturada foi aplicada com uma estrutura prévia composta por 21 questões.

O processo de pesquisa foi iniciado com a realização de um estudo piloto com a finalidade de conhecer e explorar o campo de estudo. A partir disso, o processo de pesquisa apresentou duas fases distintas. A primeira foi uma triagem, e na segunda, os sujeitos que obtiveram o score igual ou superior a 9 pontos no inventário "foram convidados, através de telefonema ou via correio eletrônico, a preencherem o questionário ${ }^{8} \mathrm{e} \mathrm{a}$ realizarem a entrevista semiestruturada. ${ }^{10,11}$

A análise dos dados das entrevistas foi realizada de acordo com o método hermenêutico-dialético ${ }^{12}$ e seguiu três passos de operacionalização dos dados: ordenação dos dados a partir de leitura prévia das entrevistas, classificação dos dados com o estabelecimento das categorias e análise final. ${ }^{13}$ É importante destacar aqui que a aprendizagem dos atletas é uma das categorias apresentadas na dissertação.

Para a realização da pesquisa, foram tomados todos os cuidados éticos (termos de consentimento livre e esclarecido), sugeridos pela Universidade Federal do Rio Grande do Sul, com base na Resolução no 196 , de 10 de outubro de 1996, que define diretrizes e normas regulamentadoras de pesquisas envolvendo seres humanos. ${ }^{14}$

\section{RESULTADOS E DISCUSSÃO}

Os atletas que fizeram parte da pesquisa e responderam à entrevista semiestruturada (11 atletas no total) iniciaram a prática esportiva, em média, aos 35 anos de idade. Todos participavam de competições e treinavam regularmente com frequência média de quatro vezes por semana, em torno de $45 \mathrm{Km}$ totais de treinamento semanal. A maioria (9) era vinculada a algum clube ou

A decisão do convite para os atletas que obtiveram o score igual ou superior a 9 pontos no inventário SOC foi em função de que nenhum dos 83 atletas avaliados na primeira etapa da pesquisa realizou 12 pontos no inventário e pela pouca disponibilidade dos sujeitos em realizarem a entrevista. 
associação de corredores. Com relação a suas atividades profissionais, o grupo entrevistado apresentou seis sujeitos aposentados e cinco não aposentados. No entanto, quatro atletas não exerciam nenhuma atividade profissional e sete continuavam ativos em alguma profissão/ ocupação.

Os atletas, em suas entrevistas, pontuaram aprendizagens que desenvolveram com os anos de prática no esporte competitivo, isto é, uma aprendizagem desenvolvida através da corrida. Como exemplos de resposta, temos: "Sim, a disciplina e solidariedade" (A1 - 52 anos) e "Me trouxe mais organização" (A6 - 58 anos).

Outros depoimentos citam aprendizagens desenvolvidas com o esporte, com o acréscimo $\mathrm{da}$ construção de valores que funcionaram como mecanismos internos que deram suporte ao desenvolvimento de outras atividades em suas vidas. A aprendizagem funcionou como uma via de dupla direção, na qual a corrida trouxe qualidades para ela própria, como também para a vida dos sujeitos.

"[...] espirito de equipe atépara dentro da familia, né, eu acho que tudo isso é importante, porque isso vem refletirpara dentro da tua familia né" (A2 60 anos).

"Como conviver com as pessoas de vários temperamentos. No trabalho, no dia a dia, mas a corrida em si treinando sozinho ou em companbia de certas pessoas sempre varia o comportamento das pessoas, mas o meu é sempre o mesmo, sempre alegre, sou sempre uma pessoa para cima. Isso ai eu aprendi através das corridas. Ela sempre me trouxe um bom comportamento, desfruto uma vida saudável em cima da corrida" (A11- 65 anos).

"Eu vejo o seguinte, eu era um cara que tentava alguma coisa, antes de começar se a coisa era meio complicada, meio dificil, eu desistia. Eu aprendi a ser tenaz correndo, porque quando a gente tá correndo competitivo especialmente chega uma bora que tu pensa assim, puxa... quando tu tá muito cansado... O que eu tô fažndo aqui...para que eu tô correndo, podia estar em casa agora tomando uma cervejinha, assistindo televisão numa boa, a vontade é sentar no meio fio e parar, mas ai a gente aprende que para ganhar... para você concluir... você chegar, você tem que ter força de vontade" (A10 - 74 anos).

Os depoimentos denunciam diferentes formas de aprendizado; aprenderam melhores maneiras de lidar com o outro e aperfeiçoar as relações sociais, desenvolveram valores pessoais, aprenderam a conviver com situações adversas e aprimoraram sua forma de enfrentar desafios. A partir dos relatos, fica clara a disposição desses atletas ao aprendizado, quando apontam que os valores cultivados com o esporte se espalharam para outros setores de suas vidas. Tais características psicológicas positivas e valores elencados pelos atletas são aprendizagens de atitudes desenvolvidas com a experiência de praticarem o esporte competitivo. ${ }^{15}$

A atividade física e o esporte promovem em seus praticantes uma aprendizagem contínua, quando o indivíduo vê algum significado na atividade. Aprender sobre o esporte vai além de praticá-lo, pois significa dominar um conhecimento que gera cuidados pessoais e possibilidade de autonomia. ${ }^{16}$ Autonomia em procurar respostas a seus problemas e optar por recursos de auxílio para resolver dificuldades ou potencializar o desempenho através de informações provenientes de meios de comunicação, como internete revistas esportivas; ou ainda através da literatura especializada no assunto, que está se tornando cada vez mais reconhecida como uma área específica da Educação. ${ }^{17}$

"A gente lê: internet, revista de esporte"(A9 - 51 anos).

"[...] en estudo, [...] eu leio as questões do aeróbico, anaeróbico, porque eu tenho que fazer musculação, como a gente pode fazer para ter um melhor desempenho, mas a fim de conbecimentos gerais"(A6 - 58 anos).

[protetorpara o bálux-arrancamento de unba] "Fui descobrir se existia uma coisa para isso, ai eu soube que tinha para unha encravada que na verdade éo mesmo. Em seguida procurei... Procureipela internet, aí eu procurei em Porto Alegre em casa de ortopedia eachei"(A9- 51 anos). 
"[...] leio muito, eu pesquiso muito. Na minha casa eu tenho muitos livros sobre nutrição, educação física, sobre treinamento eu tenho tudo, tudo, tudo"(A2 - 60 anos).

Os corredores também utilizaram os locais de competições para observar e aprender questões relativas ao esporte, como por exemplo, o movimento, de acordo com o atleta 7 , ou utilizaram os corredores de mais sucesso como modelos para aprender e copiar o que eles fazem.

"Eu vou numa competição, eu corria $10 \mathrm{Km}$, boje eu já não corro mais esta, mas eu vou mais para captar orientação, pois cada prova você aprende alguma coisa, na hora você vê um colega e aprende, aprende até o movimento" (A7-75 anos).

"[...] eu vou na São Silvestre eu procuro ver como os caras se alimentam, como eles treinam, é copiar" (A8 -73 anos).

"Suplementos alimentares - porque os bons caras usam... Em nivel mundial, quem não usar não consegue treinar muito. Eu se treinar sem nada resisto 30-40 minutos. Então tenho que tomar... Tem que tomar."(A4 - 57 anos).

As visitas de observação aos momentos de competição apresentam como finalidade a captação de informações a respeito do esporte. Esse foi o local eleito por dois atletas (A7; A8). A via de acesso ao conhecimento escolhida não possuía clara intenção de se tornar um meio que gerasse aprendizagem. Entretanto, para quem estava lá observando, havia a intenção de aprender. O tipo de aprendizagem que se processou é denominada aprendizagem informal. A via informal é a maneira mais fiel para se pensar a educação ao longo de toda vida, pois é através dela que todos os espaços e momentos são oportunidades reais para o aprendizado e o crescimento. ${ }^{18,19}$

Os atletas utilizaram as relações que estabelecem com a prática da corrida como uma maneira de manter seu nível de funcionamento no esporte. $\mathrm{O}$ contato com amigos e colegas também apresenta a finalidade de trocar experiências e aprender mais sobre o esporte, desenvolvendo os recursos para solucionar dificuldades.
"[...] eu troco ideias com amigos meus que têm melhores condiçöes que eu para comprar [...] O laço de amizade na corrida, cada prova que você vai aquele laço aumenta. É difícil ir numa corrida e assim, olha eu não conheci outra pessoa, ai eu vou mentir, né, falar a verdade, que cada corrida em cada cidade que você vai aumenta o círculo de amizade e de conbecimento e isso é muito bom. Conbecimento, a gente passa troca ideia, a gente fazpergunta, o que a gente vai fazer para melhorar" (A11- 65 anos).

O grupo de amigos para adultos de meia idade, segundo a literatura, ${ }^{20}$ apresenta pouca importância. Os adultos de meia idade geralmente estão envolvidos com outros papéis e por isso as relações de amizade são menos presentes e quase desnecessárias. Com a continuidade da vida (velhice), as amizades aumentam e os amigos podem desempenhar papéis mais importantes, como de companhia para o riso e para compartilhar atividades. No entanto, o esporte produz nos indivíduos efeitos favoráveis no processo de desenvolvimento social, tanto em indivíduos sadios quanto em indivíduos com os mais variados tipos de patologias ${ }^{15}$. Por isso, as constatações encontradas na literatur $\mathrm{a}^{20}$ parecem distintas do grupo de atletas em questão.

Apesar de se tratar de pessoas que também estão na meia idade e velhice, o círculo de amizades é entendido por eles como algo importante para dar sustentação à própria prática, pois proporciona uma troca de saberes entre os atletas. Além disso, o esporte parece ainda proporcionar maior contato com outras pessoas, permitindo maior inserção social.

Por fim, como outra forma de aprender sobre as questões relativas à pratica esportiva, está no auxílio de pessoas especializadas no esporte que trazem informações e possuem influência educativa nos atletas. É a utilização de um conhecimento mais formalizado para suprir necessidades e gerar crescimento.

Através da leitura, recomendacões do profissional médico e treinador (A1-52 anos).

[...] eu conheci uma estudante de Educação Física que ela passava os treinamentos para mim, 
progressivos, vários tipos de treinamento, então eu fui aprendendo. Muitos anos aprendi, então boje eu sei treinar. Eu sozinho sei, como eu tenho que recomeşar, o que en tenho que fazer... tempo e tudo mais... e carga... e tudo isso (A10- 74 anos).

A prática esportiva em si traz aprendizado, um aprendizado que encontra lugar de aplicação em outros meios. Além disso, a literatura, assim como os profissionais especializados na área esportiva; os locais de competição; os meios de comunicação como internet revistas esportivas e o próprio ambiente onde habitam os atletas, geram distintas formas de aprendizado que, por uma clara necessidade de adaptação, tornaram os atletas agentes responsáveis por sua educação.

Distintos e diversos espaços para captar os conhecimentos foram necessários a fim de promover o desenvolvimento pessoal. Com base no texto de Okuma, ${ }^{16}$ o qual aponta uma proposta educacional para a atividade física que vai além da simples reprodução de movimentos orientados por um profissional qualificado, visando ao desenvolvimento do praticante e não somente à melhora da aptidão física, da funcionalidade ou da saúde, podemos discutir que os atletas entrevistados possuem as características de independência na condução de suas próprias necessidades, de autonomia com relação a sua prática esportiva e de controle das suas perdas a partir do aprendizado que desenvolveram com elas. Outra constatação é relativa à capacidade que os atletas possuem de aprender e, a partir desses aprendizados, constroem um conhecimento que permite se adaptarem a qualquer dificuldade que possa apresentar, pois possuem no grupo de amigos um apoio importante, assim como no treinador ou no próprio médico, que permite crescimento e desenvolvimento no esporte.

É uma forma de educação genuinamente desenvolvimental, pois se distancia da ideia de que a aprendizagem se processa apenas através da ação formal da escola ou apenas da transmissão do conhecimento realizado por outrem. Com responsabilidade e autonomia, os atletas se autoeducam, promovendo o crescimento tanto no esporte quanto na vida pessoal. ${ }^{21}$

\section{CONSIDERAÇÕES FINAIS}

Os atletas corredores participantes da pesquisa possuem a prática esportiva como um hábito instituído em suas vidas. O gosto e o entusiasmo pelo esporte são a principal motivação desses sujeitos.

A partir dessa motivação pelo esporte, os atletas, frente aos anos que praticaram a corrida, desenvolveram aprendizagens de valores e atitudes que de certa forma garantiram desenvolvimento pessoal e no esporte, e os auxiliaram em atividades cotidianas. Além disso, é importante destacar que, para obter informações e aprenderem com as dificuldades advindas do esporte, vários tipos de espaços foram utilizados, tais como a internet, revistas esportivas, literatura especializada, locais de competição, grupo de amigos e pessoas especializadas na área esportiva. Todos esses ambientes e pessoas consultados demonstram que os atletas possuem autonomia diante do seu aprendizado e vão à busca da resolução dos problemas. Com isso se mostram como um grupo diferenciado de pessoas independentes na condução de suas próprias necessidades e ativas quando a ação é aprender. A educação amplia o potencial do ser humano, otimizando ações e/ ou as compensando, o que leva os atletas ao crescimento no esporte.

A prática da corrida é uma escolha e um objetivo claramente definido para o grupo e, além disso, como ficou entendido ao longo da pesquisa, esses atletas apresentam a característica de possuírem na atividade esportiva sentido que os faz perpetuar sua prática, e com isso estão construindo uma nova maneira de envelhecer.

Os atletas, por estarem em permanente contato com o novo, desempenhando atividades, aprendendo coisas diferentes, mantêm papéis sociais que lhes sejam significativos, de modo a manterem o sentido de vida. O sentido pessoal no esporte auxiliou os atletas a superarem crises e perdas ao longo da vida, e com isso obtiveram progressos no desenvolvimento numa fase que se iniciam ou que se percebem maiores declínios e perdas. 


\section{REFERÊNCIAS}

1. Shu-Chen Li, Freund A. Advances in lifespan psychology: a focus on biocultural and personal Influences. Research in Human Development 2005; 2(1-2):1-23.

2. Baltes $\mathrm{P}$. Theoretical propositions of life-Span developmental psychology: on the dynamics between growth and decline. Developmental Psychol 1987; 23(5):611-26.

3. Baltes P. A Systemic wholistic view of psychological functioning in very old age: introduction to a collection of articles from the Berlin Aging study. Psychol Aging 1997;12(3):395-409.

4. Silva M, Varela Z. O Conceito de adaptação na Terceira Idade. Arq Geriatr Gerontol 1999; 3(1):25-29.

5. Almeida, S T. O Processo de envelhecimento no esporte: compensando perdas. In : XII Simpósio Internacional do Instituto de Geriatria e Gerontologia da PUCRS; 2010 abr 15-17; Rio Grande do Sul, Brasil. Rio Grande do Sul : PUCRS; 2010.

6. Almeida S, Doll J. O Envelhecimento bemsucedido de atletas corredores. In: XII Congresso ciências do desporto e educação física dos países de língua portuguesa. Porto Alegre: UFRGS; 2008. p.1-9.

7. Delors J. Educação: um tesouro a descobrir. Brasília: Cortez; 2001.

8. Richardson R. Pesquisa social: métodos e técnicas. São Paulo : Atlas; 1999.

9. Goldim J. Manual de iniciação à pesquisa em saúde. Porto Alegre: Da Casa Editora; 1995.

10. Gil A. Métodos e técnicas de pesquisa social. São Paulo: Atlas; 1987.

11. Gaskell G. Entrevistas individuais e grupais. In: Bauer M, Gaskell G. Pesquisa qualitativa com texto, imagem e som: um manual prático. 2.ed. Rio de Janeiro: Vozes; 2003. p. 64-89.
12. Gomes R. Análise de dados em pesquisa qualitativa. In: Minayo, et al. Pesquisa social: teoria, método e criatividade. Rio de Janeiro: Vozes; 2001.p. 67-80.

13. Minayo M. O Desafio do conhecimento: pesquisa qualitativa em saúde. São Paulo: Hucitec-abrasco; 1992.

14. Agência Nacional de vigilância Sanitária ( Brasil); Resolução Federal n 169/96, 10 de Outubro de 1996. Diretrizes e Normas Regulamentadoras de Pesquisa Envolvendo seres Humanos. Diário Oficial da União 11 Out 1996.

15. Messias A, Pelosia A. A Relação entre a personalidade e a prática esportiva. In: Machado A. Psicologia do esporte : temas emergentes. Jundiaí: Ápice; 1997. p. 38-55.

16. Okuma S. Cuidados com o corpo: um modelo pedagógico de educação física para idosos. In: Freitas E, et al. Tratado de Geriatria e Gerontologia. Rio de Janeiro: Guanabara Koogan; 2002.p.1093-1100.

17. Havighurst R. Successful Aging. The Gerontologist 1976; 1(1):8-13.

18. Diouf A, Mbaye M, Nachtman Y. L'Education non formelle au Senegal - description, evaluation et perspectives. 2001 [Acesso $17 \mathrm{Nov}$ 2006] Disponível em: http://portal.unesco.org/ education/em/ev.php_URL

19. Hamadache A . Articulation de L'Éducation formelle et non formelle implications pour la formation des enseignants. 1993 [Acesso $20 \mathrm{Jul}$ 2006]. Disponível em: http://www.unesco.org/ education/pdf/44_24_f.pdf

20. Bee H. O Ciclo Vital. Porto Alegre: Artes Médicas; 1997.

21. Cachioni M, Palma L. Educação permanente: perspectiva para o trabalho educacional com o adulto maduro e idoso. In: Freitas E, et al. Tratado de Geriatria e Gerontologia. Rio de Janeiro: Guanabara Koogan; 2006. p.1457-65. 
